\title{
Evaluation of repellent activities of the essential oil of Ocimum basilicum against Anopheles mosquito and formulation of mosquito repellent cream
}

\author{
Almardi A Adam ${ }^{1}$, Salma A Ahmed ${ }^{2}$, Thana A Mohamed ${ }^{3}$, Rasha A Azrag ${ }^{2}$, Salma E Mustfa ${ }^{4}$ and Omer AA Hamdi* \\ ${ }^{1}$ Department of Chemistry, Faculty of Science and Technology, Al-Neelain University, Khartoum, Sudan \\ ${ }^{2}$ Department of Zoology, Faculty of Science, University of Khartoum, Sudan \\ ${ }^{3}$ Department of Pharmacognosy, Faculty of Pharmacy, Sudan International University, Sudan \\ ${ }^{4}$ Department of Food Science and Technology, College of Agricultural Studies, Sudan University of Science and Technology, Shambat, Khartoum North, Sudan
}

\begin{abstract}
This study was conducted to evaluate the repellent activities of the essential oils of Ocimum basilicum against Anopheles mosquito and to formulate cream repellent for mosquitoes from essential oil of O. basilicum L. Ocimum basilicum L. (Lamiaceae) commonly known as sweet basil, has been used as a traditional medicinal plant for the treatment of headaches, coughs, diarrhoea, constipation, warts, worms, and kidney malfunctions. The essential oil of the plant of $O$. basilicum was obtained by hydro-distillation and analyzed by gas chromatography coupled to mass spectrometry (GC-MS). The physical properties of essential oil were also identified. Fifty-one compounds were characterized and identified by GC-MS, comprising $99.7 \%$ of the total oil. Major compounds were linalool (18.88\%), cinnamic acid (18.31\%), and eucalyptol (8.46\%). In this work, the oil was assessed for topical repellence effects against malarial vector Anopheles mosquito in cages. The essential oil was tested at three different concentrations 2,4 and $6 \%$ of the oil. From the results obtained, the essential oil of Ocimum basilicum exhibited relatively high repellency effect $(>250$ minutes at $6 \%$ concentration). The oil was successively formulated as a cream. The formulated cream was prepared using the concentration of $6 \%$ of the essential oil. The cream was tested for repellency effect and showed same effect as the essential oil of Ocimum basilicum at the concentration of 6\%. The results achieved suggest that essential oils of Ocimum basilicum have activities repellency against female Anopheles and could be used in the form of natural repellent cream.
\end{abstract}

\section{Introduction}

Basil (Ocimum basilicum L.) is the most common species in Lamiaceae family. Ocimum genus includes about 150 species [1]. Within the species Ocimum basilicum $\mathrm{L}$, there are several varieties that differ in the general morphological structure and texture, and in the content of chemical parameters [2]. Basil chemically contains low percentage of essential oils, as well as volatile oils, linalool, lineol, geraniol and polyphenolic acids. It is used in the traditional medicine to sooth pain, treat vomiting and stress and commonly as insect repellent. Moreover, basil tea is good for treating dysentery, nausea and flatulence. The oil of the plant is beneficial for the alleviation of spasm, rhinitis mental fatigue, cold, and as a first aid treatment for wasp stings and snake bites [3]. It has been used as a folk remedy for boredom and convulsion $[4,5]$. Basil cures headache improves digestion and is also good for toothache, earache and for curing epistaxis when used with camphor. Infusion of plant is effective in cephalalgia, gouty joints, fever, otitis and snake bite [6]. The plant is effective in treatment of stomach problems, fever, cough, gout and given internally to treat cystitis, nephritis and in internal piles [7]. Malaria is the primary reason of morbidity and mortality in the Sudan, with 7.5 million cases and 35, 000 deaths recorded annually [8]. Larviciding has the greatest control impact on mosquito populations, because the larvae are concentrated, immobile and accessible. The use of conventional pesticides in the water sources, however, bring many risks to people, their animals, wildlife and/or the environment. In recent times, the use of environment -friendly and biodegradable natural insecticides of plant origin (botanicals) to control insect vectors of diseases and others pests is very helpful and proved to be promising; therefore, aromatic plants and their essential oils, for example, are considered to be very important sources of many compounds that are used in different respects. Essential oils and some plant-extracts are still an important natural resource and more promising for pesticides/insecticides to control mosquitoes and several other pests [9-13]. Natural product can be used either by itself as powders or with suitable carrier or additives after being extracted by a proper solvent(s) and then formulated as required (Satriana 1983). Oils from some Ocimum spp. have been shown to repel insects and have larvicidal activity against houseflies, blue bottle flies, and mosquitoes [12]. Repellency against the adult females of Culexpipiens was observed by essential oils extracted from the dried foliage of O. basilicum [14]. The present study aims to evaluate the repellent activity of essential oil extracted from O. basilicum $L$ against Anopheles mosquito and to formulate cream repellent for mosquitoes from essential oil of $O$. basilicum $\mathrm{L}$.

${ }^{\star}$ Correspondence to: Omer Abdalla Ahmed Hamdi, Department of Chemistry, Faculty of Science and Technology, Al-Neelain University, Khartoum, Sudan, Tel: +249 92079 0284; E-mail: omerhamdi2001@hotmail.com

Key words: Ocimum basilicum, linalool, cinnamic, gas chromatography-mass spectrometry (GC-MS), repellent activity, Anopheles mosquito

Received: April 16, 2019; Accepted: April 30, 2019; Published: May 03, 2019 


\section{Material and methods}

\section{Plant materials and hydro distillation of essential oil}

The plant leaves were collected from Omdurman area, Sudan and washed with water to remove mud and dust particles. Sweet basil was weighed, and stems were separated manually from each other and dried under room temperature for three days. For distillation of essential oil, $1 \mathrm{Kg}$ of sweet basil was ground and subjected to hydro distillation for 4 hours using Clevenger apparatus. The essential oil was received in a special container and then stored in sealed vials at $+4^{\circ} \mathrm{C}$ until tested and analyzed. The essential oil was calculated as a percentage based on dried weight.

\section{Gas chromatography-mass spectrometry analysis $\mathbf{2 . 2}$}

The qualitative and quantitative analysis of the sample (essential oil) was carried out by using GM/MS technique model (GC/MSQP2010-Ultra) from Japans 'Simadzu Company, with serial number 020525101565SA and capillary column (Rtx-5 ms-30 m $\times 0.25 \mathrm{~mm}$ $\times 0.25 \mu \mathrm{m}$ ). The sample was injected by using split mode, instrument operating in EI mode at $70 \mathrm{eV}$. Helium as the carrier gas passed with flow rate $1.69 \mathrm{ml} / \mathrm{min}$, the temperature program was started from $50^{\circ} \mathrm{C}$ with rate $7^{\circ} \mathrm{C} / \mathrm{min}$ to $180^{\circ} \mathrm{C}$ then the rate was changed to $10^{\circ} \mathrm{C} /$ min reaching $280^{\circ} \mathrm{C}$ as final temperature degree. The injection port temperature was $300^{\circ} \mathrm{C}$. the ion source temperature was $200^{\circ} \mathrm{C}$ and the interface temperature was $250^{\circ} \mathrm{C}$.The sample was analyzed by using scan mode in the range of $40-500 \mathrm{~m} / \mathrm{z}$ charges to ratio and the total run time was 28 minutes.Identification of components for the sample was achieved by comparing their retention times and mass fragmentation patents with those available in the library of National Institute of Standards and Technology (NIST). Results were recorded.

\section{Rearing of mosquitoes larvae}

The Anopheles mosquito's larvae, were collected at various sites in Khartoum state; the larvae were transferred separately in metal dishes (40 $\mathrm{cm}$ diameter) and their rearing was continued until pupation. The larvae were reared continuously for several generations and kept under $25-30^{\circ} \mathrm{C}, 70-80 \%$ relative humidity and photoperiod of $13: 11 \mathrm{~h}$ (light/dark) from $4^{\text {th }}$ May to 15 September 2018 (Training Institute, Khartoum, Sudan). The adults were reared in humidified cages and supplied with $10 \%$ sugar solution and $10 \%$ multivitamin syrup supplied in plates. Female mosquitoes were periodically blood-fed on restrained rabbits to obtain protein used principally for egg production. Under these conditions, the full development from egg to adult lasted about 35 weeks. Third instars of Anopheles mosquito larvae were used in the repellency test.

\section{Repellency tests}

The essential oils were evaluated for their repellent activities against Anopheles mosquito using the human-bait technique [15]. Firstly, essential oil was diluted in ethanol and prepared 2, 4, and 6\% concentrations. For each test, 10 disease free, laboratory- reared female mosquitoes were placed into separate laboratory cages $(45 \times 38 \times 38$ $\mathrm{cm}$ ). Before each test, the volunteer's skin was washed with unscented soap and the tested essential oil was applied from the elbow to the fingertips. In each cage one arm was inserted for one test concentration and the other arm applied with ethanol served as control. The treated and control arms were interchanged regularly to eliminate bias. Each test concentration was repeated five times and, in each replicate, subject different volunteers to nullify any effect of colour of the skin on repellent. Volunteers were asked to follow the testing protocol.
Volunteers conducted their test of each concentration by inserting the treated and control arms alternatively into a same cage for one full minute for every five minutes. If they were not bitten within 20 minutes, then the arms were reinserted for 1 full minute for every 15 minutes, until the first bite occurred.

\section{Formulation cream for mosquito repellent}

All apparatus were washed by tap water and distilled water and then $5.2 \mathrm{~g}$ of Essential oils of basil was weighted in beaker $(500 \mathrm{ml})$ and $12.5 \mathrm{~g}$ of Vaseline and $12.5 \mathrm{~g}$ of wax were added and then the mixture were heated with stirring until all components were dissolved $57 \mathrm{~g}$ of distilled water was added with stirring until the mixture became white and a homogenous semisolid cream appeared.

\section{Results and discussion}

\section{Physical properties}

The results for Physical properties of essential oils were: Colour was light yellow, smell was intense scent, density was $0.656 \mathrm{~g} / \mathrm{cm}^{3}$ at $28^{\circ} \mathrm{C}$ and refractive index was 1.497 at $28.9^{\circ} \mathrm{C}$.

\section{Chemical composition of essential oils}

Fifty-one compounds were characterized and identified by GC-MS, comprising $100 \%$ of the total oil. The main chemicals compounds that found in essential oil were shown in figure 1 and table 1. Linalool (1, 6-octadien-3-ol, 3,7-dimethyl) (18.87\%), cinnamic acid, methyl ester(2-propenic acid, 3-phenyl-, methyl ester) (18.31 $\%)$ Eucalyptol(2-oxabicyclo[2.2.2.]octane) (8.46\%), a-Citral (2,6 octadienal , 3,7dimethyl-,(E))(6.52\%), benzoic acid,4-methyl-, methyl ester (4.85\%), beta-citral (2,6-Octadienal, 3,7-dimethyl-,(Z)-)(4.79\%), Eugenol (3.32\%),trans-.alpha.-Bergamotene(3.13\%),Geraniol(2.45\%), tau.-cadinol (2.36\%), Cyclohexane, 1-ethenyl-1-methyl-2,4-bis(1methylethenyl)-,[1S(1.alpha.,2.beta.,4.beta.)] (1.97\%), 3-Cyclohexen1-ol, 4-methyl-1-(1methylethyl)-,(R)-(1.84Phenol,2-methoxy-4-(2propenyl)-, acetate (1.73\%), and $\alpha$-Terpineol (1.33\%). According to the chromatogram in figure 3.1, Linalool, cinnamic acid and Eucalyptol are found main components. In a study done in Bangladesh for Ocimum basilicum, linalool and geraniol were reported as the main components [16]. In the oils, obtained from aerial parts of O. basilicum grown in Colombia and Bulgaria, linalool and methyl cinnamate were reported as major components of volatile oils respectively $[17,18]$.

\section{Repellency assessment of the oil}

In this study, the results for repellency of essential oil of Ocimum basilicum against mosquito Anopheles under laboratory condition were given in table 2. Ocimum basilicum provided repellency of 125.0, 200.0 and 270.0 minutes at 2,4 , and $6 \%$ concentrations respectively. From these results it could be concluded that, increasing in the concentration of the essential oil, extends the repellency time. There were significant differences in repellency among the different concentrations of each essential oil against Anopheles. On the other hand, the ethanol applied arm served as control provided maximum 10 minutes repellency. Among the concentrations 6\% of essential oil of Ocimum basilicum, provided more than $4 \mathrm{~h}$ repellency, while the concentration $4 \%$ provided more than $3 \mathrm{~h}$ repellency, but concentration $2 \%$ give repellency of less than $2.30 \mathrm{~h}$. The essential oil of Ocimum basilicum used in this study did not cause skin irritation, hot sensations or rashes on the arms of the test volunteers during the study period. The results obtained in this work indicated that essential oils that extracted from Ocimum basilicum showed promising repellent activity against 
Table 1. Chemical composition of the essential oil extracted from Ocimum basilicum $\mathrm{L}$

\begin{tabular}{|c|c|c|c|c|}
\hline ID\# & Name & Ret. Time & Area & Area $\%$ \\
\hline 1 & .alpha.-Phellandrene & 4.561 & 114422 & 0.04 \\
\hline 2 & .alpha.-Pinene & 4.693 & 970358 & 0.30 \\
\hline 3 & Camphene & 4.966 & 249805 & 0.08 \\
\hline 4 & Benzaldehyde & 5.239 & 312644 & 0.10 \\
\hline 5 & Bicyclo[3.1.0]hexane, 4-methylene-1-(1-methylethyl)- & 5.395 & 1370547 & 0.42 \\
\hline 6 & Bicyclo[3.1.1] heptane, 6,6-dimethyl-2-methylene-, (1S)- & 5.471 & 2542220 & 0.78 \\
\hline 7 & 5-Hepten-2-one, 6-methyl- & 5.629 & 624862 & 0.19 \\
\hline 8 & .beta.-Myrcene & 5.677 & 1480810 & 0.46 \\
\hline 9 & Cyclohexene, 1-methyl-4-(1-methylethylidene)- & 6.198 & 182736 & 0.06 \\
\hline 10 & o-Cymene & 6.359 & 732353 & 0.23 \\
\hline 11 & D-Limonene & 6.437 & 1961962 & 0.60 \\
\hline 12 & Eucalyptol & 6.508 & 27434351 & 8.46 \\
\hline 13 & 1,3,6-Octatriene, 3,7-dimethyl-, (Z)- & 6.783 & 1750671 & 0.54 \\
\hline 14 & gamma.-Terpinene & 7.026 & 556179 & 0.17 \\
\hline 15 & Bicyclo[3.1.0]hexan-2-ol,2-methyl-5-(1-methylethyl)-, (1.alpha.,2.beta.,5.alpha.)- & 7.239 & 1872400 & 0.58 \\
\hline 16 & Ethyl 2-(5-methyl-5-vinyltetrahydrofuran-2-yl)propan-2-yl carbonate & 7.321 & 860073 & 0.27 \\
\hline 17 & L-Fenchone & 7.661 & 6574267 & 2.03 \\
\hline 18 & 1,6-Octadien-3-ol, 3,7-dimethyl- & 7.889 & 61247701 & 18.87 \\
\hline 19 & Bicyclo[2.2.1]heptan-2-ol, 1,3,3-trimethyl- & 8.212 & 4734233 & 1.46 \\
\hline 20 & $(+)$-2-Bornanone & 8.830 & 2348885 & 0.72 \\
\hline 21 & Isoborneol & 9.285 & 3368002 & 1.04 \\
\hline 22 & 3-Cyclohexen-1-ol, 4-methyl-1-(1-methylethyl)-, (R)- & 9.488 & 5983669 & 1.84 \\
\hline 23 & .alpha.-Terpineol & 9.765 & 4330300 & 1.33 \\
\hline 24 & (-)-Myrtenol & 9.890 & 1173728 & 0.36 \\
\hline 25 & Fenchyl acetate & 10.297 & 420327 & 0.13 \\
\hline 26 & 2,6-Octadienal, 3,7-dimethyl-, (Z)- & 10.720 & 15545037 & 4.79 \\
\hline 27 & Geraniol & 10.977 & 7935392 & 2.45 \\
\hline 28 & 2,6-Octadienal, 3,7-dimethyl-, (E)- & 11.303 & 21139820 & 6.52 \\
\hline 29 & Bornyl acetate & 11.614 & 1007985 & 0.31 \\
\hline 30 & Benzoic acid, 4-ethenyl-, methyl ester & 12.026 & 15723394 & 4.85 \\
\hline 31 & Geranic acid & 12.293 & 653171 & 0.20 \\
\hline 32 & Geranic acid & 12.596 & 539897 & 0.17 \\
\hline 33 & Eugenol & 13.037 & 10769026 & 3.32 \\
\hline 34 & Geranyl acetate & 13.418 & 1092718 & 0.34 \\
\hline 35 & 2-Propenoic acid, 3-phenyl-, methyl ester & 13.565 & 59402173 & 18.31 \\
\hline 36 & Cyclohexane,1-ethenyl-1-methyl-2,4-bis(1-methylethenyl)-, [1S-(1.alpha.,2.beta.,4.beta.)]- & 13.652 & 6396144 & 1.97 \\
\hline 37 & Caryophyllene & 14.204 & 3542971 & 1.09 \\
\hline 38 & trans-.alpha.-Bergamotene & 14.418 & 10156451 & 3.13 \\
\hline 39 & .alpha.-Guaiene & 14.500 & 1433373 & 0.44 \\
\hline 40 & Humulene & 14.825 & 2049616 & 0.63 \\
\hline 41 & $\begin{array}{l}\text { 1H-Cyclopenta[1,3]cyclopropa[1,2]benzene, octahydro-7-methyl-3-methylene-4-(1-methylethyl)-,[3aS-(3a.alpha.,3b. } \\
\text { beta.,4.beta., }\end{array}$ & 14.984 & 726206 & 0.22 \\
\hline 42 & 1,6-Cyclodecadiene,1-methyl-5-methylene-8-(1-methylethyl)-, [S-(E,E)]- & 15.312 & 3764257 & 1.16 \\
\hline 43 & .gamma.-Elemene & 15.589 & 1817705 & 0.56 \\
\hline 44 & Azulene,1,2,3,5,6,7,8,8a-octahydro-1,4-dimethyl-7-(1-methylethenyl)-, [1S-(1.alpha.,7.alpha.,8a.beta.)]- & 15.723 & 2583104 & 0.80 \\
\hline 45 & .gamma.-Muurolene & 15.879 & 6601053 & 2.03 \\
\hline 46 & Phenol, 2-methoxy-4-(2-propenyl)-, acetate & 16.049 & 5599193 & 1.73 \\
\hline 47 & Cyclohexanemethanol, 4-ethenyl-.alpha.,.alpha.,4-trimethyl-3-(1-methylethenyl)-, [1R-(1.alpha.,3.alpha.,4.beta.)]- & 16.490 & 1248951 & 0.38 \\
\hline 48 & $\begin{array}{l}\text { 1H-Cycloprop[e]azulen-7-ol,decahydro-1,1,7-trimethyl-4-methylene-, [1ar-(1a.alpha.,4a.alpha.,7.beta.,7a.beta.,7b. } \\
\text { alpha.)]- }\end{array}$ & 17.029 & 950158 & 0.29 \\
\hline 49 & 11,11-Dimethyl-spiro[2,9]dodeca-3,7-dien & 17.123 & 1562903 & 0.48 \\
\hline 50 & Cubedol & 17.627 & 1342857 & 0.41 \\
\hline 51 & .tau.-Cadinol & 18.047 & 7658470 & 2.36 \\
\hline
\end{tabular}

Table 2. Repellent activity of essential oil extracted from Ocimum basilicum L. against Anopheles mosquito

\begin{tabular}{|c|c|}
\hline Treatments & Complete-protection time (min) \\
\hline Control & $10 \pm 0.5$ \\
\hline $2 \%$ & $125 \pm 2.9$ \\
\hline $4 \%$ & $200 \pm 2.3$ \\
\hline $6 \%$ & $270 \pm 2.9$ \\
\hline
\end{tabular}




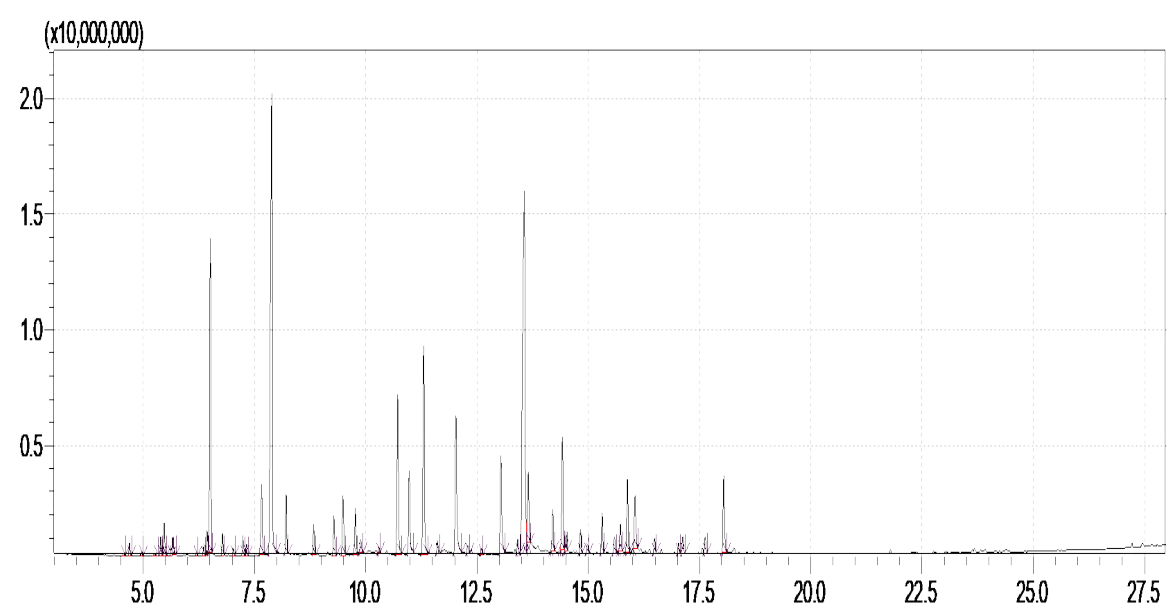

Figure 1. Gas chromatogram of essential oil of Ocimum basilicum L.

Anopheles. Nowadays, the use of plant essential oils in mosquito repellent is an alternative personal protective measure against the noxious effects of synthetic repellents on the users and environment [19]. Unlike synthetic repellents, the literature on mosquito' s botanical agents do not contain any evidence to suggest that resistance to these substances has emerged. This is most likely not due to any reason of consequence but because botanical agents are not often used in vector control [20] and also, they are mixtures of various related compounds with different modes of action and hence the development of resistance to such products is somewhat difficult [21]. Chokechaijaroenporn et al. [22] found that, repellency of the volatile oil of several basil species against Anopheles aegypti lasting between 15 and $105 \mathrm{~min}$, depending on the basil type. On other hand a study in Guina Bissau, West Africa, reported that, fresh Ocimum canum (Ocimum americamum) could reduce biting by anopheles mosquitoes about 63.6\%. Moreover, the repellency of the plant species including $O$. kilimandscharium and $O$ Suave with high biting protection reached (83 to $91 \%$ ) and feeding inhibition (71.2 to $92.5 \%)$, respectively. Other essential oils e.g. oil of turmeric, citronella grass, and citronella cream were shown to possess repellency against mosquito $[23,24]$.

Each value represents mean \pm Standard deviation. Values in the same column with different superscript letter are significantly different. Cream was prepared with different concentrations (2, 4 and 6\%) of Ocimum basilicum L oil.

\section{Conclusion}

From this research it concluded that, the essential oil extracted from Ocimum basilicum L contains many bioactive compounds such as: Linalool, cinnamic acid and Eucalyptol. Moreover, the cream prepared from basil essential oil has repellent activity and increasing skin moisture. The higher concentration of the essential oils of basil in the lotion can enhance the effect of repellent.

\section{Acknowledgement}

This work was financially supported by the Scientific Research and Innovation, Ministry of Higher Education and Scientific Research, Sudan.

\section{References}

1. Pushpangadan P, Bradu BL (1995) Advances in horticulture. Medicinal and aromatic plants. Malhotra Publishing House., India, 11: 627-657.
2. Grayer RJ, Kite GC, Goldstone J, Bryan SE, Paton A, et al. (1996) Intraspecific taxonomy and essential oil chemotypes in sweet basil, Ocimum basilicum. Phytochemistry 43: 1033-1039.

3. Lawrence BM (1985) A review of the world production of essential oil. Perfumes Flavors 10: 2-16.

4. Oliveira JS, Porto LA, Estevam CS, Siqueira RS, Alves PB, et al. (2009) Phytochemical screening and anticonvulsant property of Ocimum basilicum leaf essential oil. Bol Latinoam Caribe 8: 195-202.

5. Arthi N, Murugan K (2010) Larvicidal and repellent activity of Vetiveria zizanioides L, Ocimum basilicum Linn and the microbial pesticide spinosad against malarial vector, Anopheles stephensi Liston (Insecta: Diptera: Culicidae). J Biopesticides 3: 199-204.

6. Kirtikar KR, Basu BD (2003) Indian Medicinal Plants with Illustrations. ( $2^{\text {nd }}$ edn), Oriental Enterprises Uttaranchal, India: 2701-2705.

7. Nadkarni KM (2005) The Indian Plants and Drugs. Shrishti Book Distributors, New Delhi, India: 263.

8. Abdalla HB (2007) Insecticide resistance in malaria vectors in Central Sudan University of Witwatersrand, Johannesburg, RSA.

9. Harborne JB (1980) Plant phenolics. Encyclopedia of Plant Physiology, Secondary Plant Products. Berlin Springer-Verlag, Heidelberg New York, USA, 8: 329-395.

10. El Sayed BB (1992) Susceptibility of Anopheles arabiensis and Culexquinqe fasciatus larvae to some control agents in Khartoum state. University of Khartoum, Sudan.

11. Chavasse DC, Yap HH \& World Health Organization. Division of Control of Tropical Diseases. (1997)? Chemical methods for the control of vectors and pests of public health importance. Availabe from: https://apps.who.int/iris/handle/10665/63504

12. Abo-Elseoud MA, Sorhan MM, Omar AE, Helal MM (2005) Biocides formulation of essential oils having antimicrobial activity. Arch Physiopathology Plant Protection 38: $175-184$.

13. Satriana MJ (1983) Insecticide Manufacturing Recent Processes and applications. Nayes Data Corporation. Park Ridge, New Jersey USA.

14. Sienkiewicz M, Lysakowska M, Pastuszka M, Bienias W, Kowalczyk E (2013) The potential of use basil and rosemary essential oils as effective antibacterial agents. Molecules 18: 9334-9351.

15. Fradin MS, Day JF (2002) Comparative efficacy of insect repellents against mosquito bites. New Eng J Med 347: 13-18.

16. Mondello L, Zappia G, Cotroneo A, Bonaccorsi I, Chowdhury JU, et al. (2003) Studies on the chemical oil-bearing plants of Bangladesh. Part VIII. Composition of some Ocimum oils, O. basilicum L. var. purpurascens; O. sanctum L. green; O. sanctum L. purple; O. americanum L., citral type; O. americanum L., camphor type. Flav Fragr J 17: 335-340.

17. Vina A, Murillo E (2003) Essential oil composition from twelve varieties of basil (Ocimum spp) grown in Colombia. J Brazil Chem Soci 14: 744-749.

18. Ngassoum M, Jirovetz L, Buchbauer G (2001) SPME/GC/MS analysis of headspace aroma compounds of the Cameroonian fruit Tetrapleura tetraptera (Thonn.) Taub. Eur Food Res Techn 213: 18-21. 
19. Thorsell A, Svensson P, Wiklund L, Sommer W, Ekman R, et al. (1998) Suppressed neuropeptide Y (NPY) mRNA in rat amygdala following restraint stress. Regulatory peptides $75: 247-254$.

20. Shaalan EAS, Canyon D, Younes MWF, Wahab HA, Mansour AH (2005) A review of botanical phytochemicals with mosquitocidal potential. Environ Inter 31: 1149-1166.

21. Mulla MS, Su T (1999) Activity and biological effects of neem products against arthropods of medical and veterinary importance. J Am Mosq Control Assoc 15: 133152. [Crossref]
22. Chokechaijaroenporn O, Bunyapraphatsora N, Kongchuensin S (1994) Mosquito repellent activities of Ocimum basilicum volatile oils. Phytomedicine 1: 135-139. [Crossref]

23. Rajkumar S, Jebanesan A (2007) Repellent activity of selected plant essential oil against the material fever mosquito anapheles stephens. J Trop Biomed 24: 71-75. [Crossref]

24. Rajkumar S, Jebanesan A (2008) Bioactivity of flavoniod compounds from Poncirus trifoliate L.(family:rutaceae) against the dengue vector, aedes aegypti (Depteria: culicidea). J Parasitol Res 104: 19-25. [Crossref]

Copyright: (92019 Adam AA. This is an open-access article distributed under the terms of the Creative Commons Attribution License, which permits unrestricted use, distribution, and reproduction in any medium, provided the original author and source are credited. 